\title{
Numerical Simulations of GFRP-Reinforced Columns Having Polypropylene and Polyvinyl Alcohol Fibers
}

\author{
Liaqat Ali $\left(\mathbb{D},{ }^{1}\right.$ Ahsan Nawaz $\mathbb{D}^{1},{ }^{1}$ Yong Bai, ${ }^{1}$ Ali Raza, ${ }^{2}$ Muhammad Kashif Anwar, \\ Syyed Adnan Raheel Shah, ${ }^{2}$ and Syed Safdar $\operatorname{Raza}^{3}$ \\ ${ }^{1}$ College of Civil Engineering \& Architecture, Zhejiang University, Hangzhou 310058, China \\ ${ }^{2}$ Department of Civil Engineering, Pakistan Institute of Engineering and Technology, Multan 66000, Pakistan \\ ${ }^{3}$ Department of Civil Engineering, Bahauddin Zakariya University, Multan 66000, Pakistan \\ Correspondence should be addressed to Liaqat Ali; drali169@zju.edu.cn and Ahsan Nawaz; ahsanklasra@zju.edu.cn
}

Received 27 August 2020; Revised 17 September 2020; Accepted 21 September 2020; Published 9 October 2020

Academic Editor: Mostafa M. A. Khater

Copyright (c) 2020 Liaqat Ali et al. This is an open access article distributed under the Creative Commons Attribution License, which permits unrestricted use, distribution, and reproduction in any medium, provided the original work is properly cited.

The present investigation aims to propose a numerical model for assessing the complex damaging response of glass fiberreinforced polymer- (GFRP-) reinforced concrete columns having hybrid fibers and confined with GFRP spirals (GFHF columns) under concentric and eccentric compression. Fiber-reinforced concrete (FRC) consists of polyvinyl alcohol fibers (PVA) and polypropylene fibers (PF). A total of six GFHF circular columns were constructed having a circular cross section of $250 \mathrm{~mm}$ and a height of $1200 \mathrm{~mm}$. A commercial package ABAQUS was used for the finite element analysis (FEA) of the GFHF columns by using a modified concrete damage plastic (CDP) model for hybrid fiber-reinforced concrete (HFRC). The damaging response of GFRP bars was defined using a linear elastic model. The results depicted that the failure of GFHF columns occurred either in the upper or in the lower half portion with the rupture of GFRP longitudinal bars and GFRP spirals. The decrease in the pitch of GFRP spirals led to an improvement in the axial strength (AS) of GFHF columns. The eccentric loading caused a significant reduction in the AS of columns. The comparative study solidly substantiates the validity and applicability of the newly developed FEA models for capturing the AS of GFHF columns by considering the axial involvement of longitudinal GFRP bars and the confinement effect of transverse GFRP spirals. So, the suggested numerical model having a complex system of equations for HFRC can be used for the accurate analysis of HFRC members.

\section{Introduction}

The tendency of steel subjected to corrosion results in a substantial decrease in the service life of concrete structures made of steel reinforcement by lowering their strength and ductility. To avoid corrosion of steel bars, it is necessary to apply certain protective practices such as epoxy coatings and sacrificial cathodes which leads to additional cost. Glass fiber-reinforced polymer (GFRP) material became the most potential substitute having characteristics like lightweight, low density, high resistance, low thermal conductivity, electromagnetic susceptibility, and, most specially, high resistance to corrosion [1-4]. These anisotropic composite materials are generally more effective in aggressive and corrosive conditions, to minimize the running costs while increasing the service life of reinforced concrete $[2,5]$. The decrease in the brittleness of plain concrete is the focus of advanced research. Therefore, polyvinyl alcohol (PVA) fibers and polypropylene fibers (PF) were added into the concrete in the current work to improve its ductility by reducing the brittleness. Besides, previous studies portrayed that the concrete columns reinforced with steel bars and fibers portrayed increased strength and ductility [6, 7]. There is a need to investigate the performance of reinforced columns with GFRP bars and hybrid fibers by performing experimentation and numerical simulations which is the main goal of the present work.

Due to its superior performance, the use of GFRP bars in reinforced concrete (RC) structures over the last few decades has attracted the attention of many researchers. 
For GFRP-RC slender columns, a greater lateral deflection was observed when compared with identical steel-RC columns [8]. The failure of GFRP lateral reinforcement typically occurs as a result of the bond-slip mechanism rather than rupture [9]. GFRP-RC columns have shown no balance points for the moment due to their linear elastic behavior [10]. The steel and GFRP-RC compression members demonstrated a similar behavior, except that the AS was found to be 7 percent lower for GFRP-RC columns [11]. The laterally confined GFRP-RC columns at a pitch of $76 \mathrm{~mm}$ showed the AS of 84 percent of their counterparts in steel-RC columns [12]. The GFRP bars perform well in concrete under compression due to the lower elastic modulus of GFRP bars compared with that of steel bars, and thus it is beneficial to use GFRP bars in concrete columns [13]. The axial and bending strengths were decreased, but column ductility was improved by utilizing the steel reinforcement with an equivalent amount of GFRP bars under various loading conditions [14]. The ductility of GFRP-RC columns has been improved substantially by decreasing the vertical spacing of stirrups [15-17].

The numerical simulations have become the interest of advanced research works. Different numerical models have been applied in different fields of sciences [18-21]. The finite element models (FEMs) are considered as the most effective methods for identifying the dynamic damaging behavior of fiber-reinforced polymer (FRP) composites and their contact mechanism with the concrete at minimal cost and time $[22,23]$. Several studies that carry out the finite element modeling of GFRP-RC columns could be found in the literature [24-29]. Using the concrete damaged plastic (CDP) model, the confinement of concrete compression members can be precisely described by the finite element analysis [30]. A FEM was introduced using ABAQUS which forecasted the axial response of the steel-RC and GFRP-RC columns accurately [2]. Simulation models of the finite elements accurately predicted the buckling behavior of pultruded GFRP columns [31]. Other models and simulation techniques have been used to predict the performance of output variables [32-35]. ANSYS analyzed various slender ratios for GFRPRC short columns, and a close correlation was noted among tests and FEM estimates for failure mechanisms and postpeak collapse behavior [36, 37]. In ABAQUS, the bond-slip behavior between the concrete and the FRP bars was accurately validated to obtain a strong correlation of tests with the simulated results in the postyield phases [25, 38]. FEM can model accurately the failure modes, peak loads, corresponding deflections, and load-deflection behavior of GFRPRC columns [2, 24, 39].

The structural efficiency of GFRP-RC columns with hybrid fibers (GFHF columns) has not been investigated by any researcher. Also, the finite element analysis (FEA) of these structural elements is scarce in the earlier findings. None of the previous works proposed a novel FEM for predicting the complex damage response of GFHF columns by considering a modified plasticity model for the HFRC. So, the objective of the current study is to quantitatively measure the structural behavior of corrosion resistant GFHF columns using the experimental data and numerical simulations of FEM with different pitches of GFRP spiral under different loading conditions. The simulation model of the structural performance of GFHF columns was presented due to the hybrid fibers reinforced concrete (HFRC), lateral GFRP spiral pitch, and diverse eccentric loadings. Using ABAQUS software, the FEM of all GFHF columns was done. The HFRC behavior was visualized using a modified CDP model, and the GFRP bar behavior was described by assuming that it was a linear elastic material. This research will play a pivotal role in understanding the behavior of GFHF columns, experimentally as well as numerically, and putting them into practice in the construction sector.

\section{Materials and Methods}

\subsection{Materials}

2.1.1. Concrete. In this work, good-grade OPC following the guidelines of ASTM C150 [40] was used for the production of HFRC. The fineness modulus of fine aggregate was 2.3, while the coarse aggregate of maximum size $10 \mathrm{~mm}$ was used. PF and PVA fibers lengths were $12 \pm 1 \mathrm{~mm}$ and $10 \pm 1 \mathrm{~mm}$, and their diameters were $24 \mu \mathrm{m}$ and $20 \mu \mathrm{m}$. A slump value of $90 \mathrm{~mm}$ was observed for the fresh concrete as per ASTM C143 [41]. Diverse HFRC ingredients are presented in Table 1 . On the day of column construction, six cylinders with dimensions of $150 \mathrm{~mm} \times 300 \mathrm{~mm}$ were produced and tested on the same day when specimens were examined. The average compression strength of the cylinders was $38 \mathrm{MPa}$ when measured according to ASTM C39 [42] with a deviation of 2.24 MPa.

2.1.2. GFRP Bars. Six longitudinal GFRP bars with a diameter of $14 \mathrm{~mm}$ and GFRP spirals with a diameter of $10 \mathrm{~mm}$ were used to strengthen the GFHF columns. The GFRP longitudinal bars and spirals were made utilizing E-glass fibers impregnated with additives, fillers, and thermosetting vinyl ester resin having 80 percent fiber quantity by volume. The physical and mechanical properties of GFRP bars are as shown in Table 2.

2.2. Column Construction. A total of six circular HFRC columns with longitudinal GFRP bars and transverse GFRP spirals were built in this study. Under concentric and eccentric loading conditions, these columns were tested to failure to analyze the effect of hybrid fibers, the pitch of spirals, and the load eccentricity on the structural performance of the specimens. All the columns had a diameter of $250 \mathrm{~mm}$ and a height of $1200 \mathrm{~mm}$. These column measurements were used keeping in mind the size and compression efficiency of the testing unit. These measurements also render the columns large enough to be treated as a fullsize test specimen.

All GFHF columns comprised six $14 \mathrm{~mm}$ longitudinal GFRP bars providing a $1.88 \%$ longitudinal reinforcement ratio. Usually, such a low reinforcement ratio is provided in the areas with no seismicity zones. The transverse 
TABLe 1: HFRC mix design $\left(\mathrm{kg} / \mathrm{m}^{3}\right)$.

\begin{tabular}{lccccccc}
\hline Cement content & Fine aggregates & Coarse aggregates & Water content & w/c ratio & PVA & PF & Superplasticizer \\
\hline 460 & 639 & 1090 & $175 \mathrm{avb}$ & 0.38 & 1.2 & 1.95 & 2.35 \\
\hline
\end{tabular}

TABle 2: Physical and mechanical properties of GFRP bars.

\begin{tabular}{lccccc}
\hline Material & Nominal diameter $(\mathrm{mm})$ & Area $\left(\mathrm{mm}^{2}\right)$ & Tensile strength $(\mathrm{MPa})$ & Elastic modulus $(\mathrm{GPa})$ & Strain at tensile strength $(\mathrm{mm} / \mathrm{mm})$ \\
\hline GFRP & 10 & 78 & 770 & 48 & 0.022 \\
& 14 & 154 & 810 & 50 & 0.023 \\
\hline
\end{tabular}

confinement was supported employing GFRP spirals with a diameter of $10 \mathrm{~mm}$ at a pitch of $38 \mathrm{~mm}$ and $75 \mathrm{~mm}$, giving the volumetric ratios of $2.88 \%$ and $1.46 \%$, respectively. The pitch of the GFRP spirals was prescribed to prevent GFRP bars from buckling elastically [43]. For all the columns, a concrete cover of $20 \mathrm{~mm}$ was provided. Figure 1 demonstrates the geometrical structure of a specimen with a spiral pitch of $38 \mathrm{~mm}$, and the geometrical and test descriptions of all manufactured specimens are described in Table 3.

The circular PVC pipes have been used as formwork, with an inner diameter of $250 \mathrm{~mm}$ and a wall thickness of $8 \mathrm{~mm}$. The reinforcement cages were positioned in the formwork, and HFRC was added and vibrated nonstop using an electrical vibrator during the construction activity. All the specimens were treated at room temperature and protected with sheets of polyethylene to prevent moisture loss.

2.3. Testing and Instrumentation. In the testing machine, the testing of the samples was performed at a loading rate of $0.002 \mathrm{~mm} / \mathrm{sec}$. The specimens were prepared using steel collars (100 mm long and $10 \mathrm{~mm}$ thick) and plastered on the top and bottom surfaces before testing such that end crushing of the columns could be prevented and the load could be spread equally across the cross section. By applying a compression load on the top flattened surface, the concentric columns were loaded uniformly, whereas the eccentric columns were loaded by applying a line load at the appropriate eccentricity using a steel rod positioned between the loading plates [44] as shown in Figure 2. Readings of the axial load, axial deflection, and axial strains of the specimens were recorded using a data logger connected to the test compression unit. The failure patterns and failure modes of specimens were recorded using a video camera.

\section{Finite Element Analysis}

3.1. General Methodology. This section specifically defines the FEA of GFHF columns by detailed simulation of HFRC and GFRP reinforcement behavior. For the FEA, a wellknown commercial software ABAQUS 6.14 was used. The HFRC simulations were produced by modeling it as a portion of 3D solid stress. The reinforcing bars were interpreted as 3D deformable wire elements. Modified concrete damage plasticity (CDP) model was used to describe the HFRC damage behavior that considers the influence of PF and PVA fibers. The bottom end of samples was restricted, and the top end was permitted for all degrees of freedom. The relationship between the reinforcement and HFRC was modeled by the use of "embedded area" constraint, which combines the compatible degrees of freedom of the wire elements with the requisite degrees of freedom of the concrete 3D stress elements [2]. Using the displacement control method, a uniform load of $15 \mathrm{~mm}$ on the upper surface of concentric columns was enforced while a line load of $15 \mathrm{~mm}$ was provided at the top of the eccentric specimens at the intended eccentricity keeping the boundary condition identical to that applied in the experimental study. For uniform load distribution, a steel plate with a thickness of $50 \mathrm{~mm}$ was tied on the top and bottom surfaces of the specimens. The interaction between the steel plate and the specimen surface was established using the ABAQUS "tie" constraints. The model specimens with the geometric and applied boundary conditions are shown in Figure 3.

3.2. Simulation of Plasticity, Tension, and Compression of HFRC. The accurate simulation of HFRC behavior is very significant for predicting the behavior of GFHF columns. The HFRC elastic behavior can be predicted with two parameters: Poisson's ratio assumed to be 0.2 [45] and the elastic modulus computed as $4734 \sqrt{f_{c}^{\prime}}$ [46], where $f_{c}^{\prime}=38 \mathrm{MPa}$ is the compression strength of HFRC. The nonlinear and irreversible detrimental behavior of concrete can be precisely modeled using the CDP model, which considers the isotropic compression and tensile elasticity and plasticity of isotropic damage [24, 47]. Hence, this model with some modifications has been used in the present research to describe the damaging behavior of complex HFRC.

In the CDP model, HFRC plasticity behavior can be described by five parameters: the eccentricity $(e)$, the shape factor for yielding of the surface $\left(K_{c}^{\mathrm{hf}}\right)$, the viscosity parameter $(\mu)$, the dilation angle of $\operatorname{HFRC}(\psi)$, and the ratio of biaxial to uniaxial compression yield stresses $\left(\sigma_{\mathrm{bo}}^{\mathrm{hf}} / \sigma_{\mathrm{co}}^{\mathrm{hf}}\right)$. All these variables for HFRC were changed excluding the parameter $\mu$ which was adjusted to obtain close predictions with the samples. The factor " $e$ " has a default value of 0.1 for reinforced concrete in both plain and fiber [48]. Thus, this value was used in the present research for the parameter " $e$ ". For plain concrete, the value of the parameter $\left(K_{c}\right)$ is always between 0.64 and 0.80 [49]. A strong estimate for the strength of plain concrete is obtained under low hydrostatic stresses when a value of 0.67 is used for $K_{c}$. Additionally, an appropriate prediction is obtained under high hydrostatic 


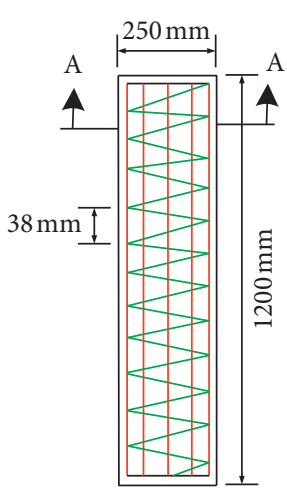

Elevation

(a)

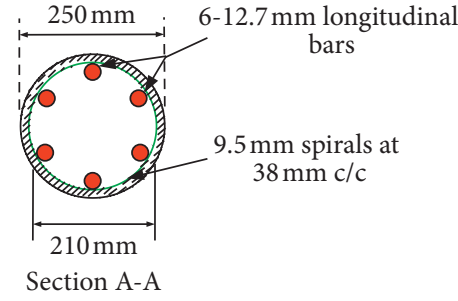

(b)

Figure 1: Drawings of a column with a spiral pitch of $38 \mathrm{~mm}$.

TABle 3: Test matrix.

\begin{tabular}{|c|c|c|c|c|c|}
\hline \multirow{2}{*}{ Specimen label } & \multicolumn{2}{|c|}{ Longitudinal reinforcement } & \multicolumn{2}{|c|}{ Transverse reinforcement } & \multirow{2}{*}{ Eccentricity (mm) } \\
\hline & Bars and diameter $(\mathrm{mm})$ & Reinforcing ratio (\%) & Spirals (mm) & Volumetric ratio (\%) & \\
\hline AA38-0ECC & $6-14 \mathrm{~mm}$ & 1.88 & $10 \mathrm{~mm} @ 38 \mathrm{~mm} \mathrm{c} / \mathrm{c}$ & 2.88 & 0 \\
\hline AA38-30ECC & $6-14 \mathrm{~mm}$ & 1.88 & $10 \mathrm{~mm} @ 38 \mathrm{~mm} c / \mathrm{c}$ & 2.88 & 30 \\
\hline AA38-60ECC & $6-14 \mathrm{~mm}$ & 1.88 & $10 \mathrm{~mm} @ 38 \mathrm{~mm} \mathrm{c} / \mathrm{c}$ & 2.88 & 60 \\
\hline AA75-0ECC & $6-14 \mathrm{~mm}$ & 1.88 & $10 \mathrm{~mm} @ 75 \mathrm{~mm} \mathrm{c} / \mathrm{c}$ & 1.46 & 0 \\
\hline AA75-30ECC & $6-14 \mathrm{~mm}$ & 1.88 & $10 \mathrm{~mm} @ 75 \mathrm{~mm} \mathrm{c} / \mathrm{c}$ & 1.46 & 30 \\
\hline AA75-60ECC & $6-14 \mathrm{~mm}$ & 1.88 & $10 \mathrm{~mm} @ 75 \mathrm{~mm} \mathrm{c/c}$ & 1.46 & 60 \\
\hline
\end{tabular}

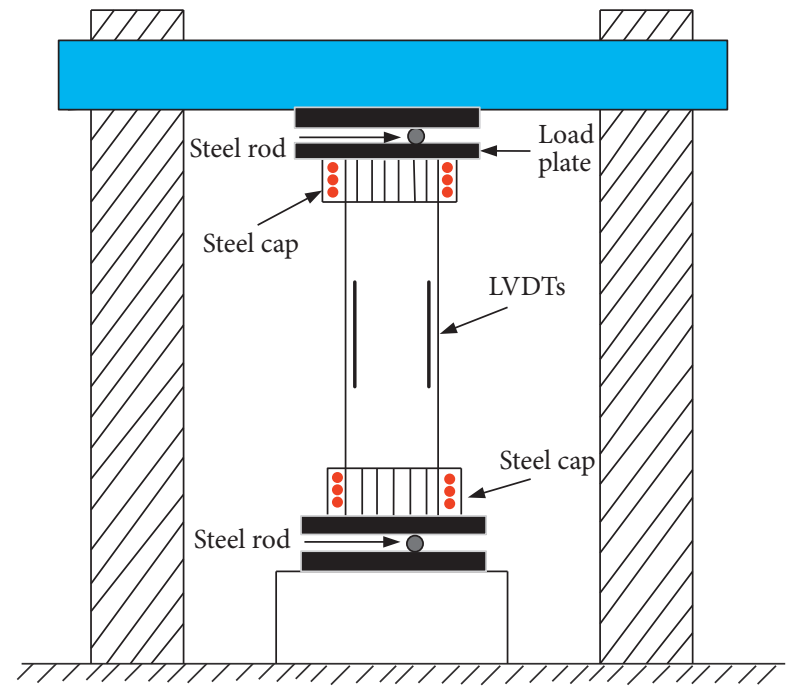

Figure 2: Basic testing arrangement for eccentric specimens.

stresses when a value of 0.70 is used for this variable [48]. Hence, when dealing with HFRC, the relationship for $K_{c}^{\mathrm{hf}}$ can be reported by presenting some enhancing constants for compression and tensile meridians, i.e., $k_{c}$ and $k_{t}[45,48]$ :

$$
K_{c}^{\mathrm{hf}}=K_{c}\left(\frac{k_{t}}{k_{c}}\right)
$$

where $k_{c}$ and $k_{t}$ represent the constants for the compression and tensile meridians of the concrete. The model for the constant $k_{c}$ HFRC has not been well-defined yet due to a deficiency of experimental testing in this area. However, the constant $k_{c}$ was defined for PVA fiber-reinforced concrete that can be reported by using equation (2) and the constant $k_{t}$ for the HFRC can be reported by using equation (3) [45]: $\lambda_{\text {pvaf }}$

$$
\begin{aligned}
k_{c} & =1+0.056 \lambda_{\mathrm{pvaf}}, \\
k_{t} & =1+0.080 \lambda_{\mathrm{pvaf}}+0.132 \lambda_{\mathrm{pf}}, \\
\lambda_{\mathrm{pvaf}} & =V_{\mathrm{pvaf}}\left(l_{\mathrm{pvaf}} / d_{\mathrm{pvaf}}\right), \\
\lambda_{\mathrm{pf}} & =V_{\mathrm{pf}}\left(l_{\mathrm{pf}} / d_{\mathrm{pf}}\right),
\end{aligned}
$$

where $V_{\mathrm{pf}}$ is the percent portion of PF by volume, $V_{\text {pvaf }}$ is the percent portion of PVA by volume, $l_{\mathrm{pf}}$ is the total length of PF, $l_{\text {pvaf }}$ is the total length of PVA, $d_{\mathrm{pf}}$ is the diameter of PF, $d_{\text {pvaf }}$ is the diameter of PVA fibers, $\lambda_{\text {pvaf }}$ is the fiber reinforcement index for PVA, and $\lambda_{\mathrm{pf}}$ is the fiber reinforcement index for PF. Due to the prevention of cracks development and propagation in the concrete by adding the hybrid fibers, the enhancement in the tensile meridian will be higher than that of the compression meridian, i.e., 


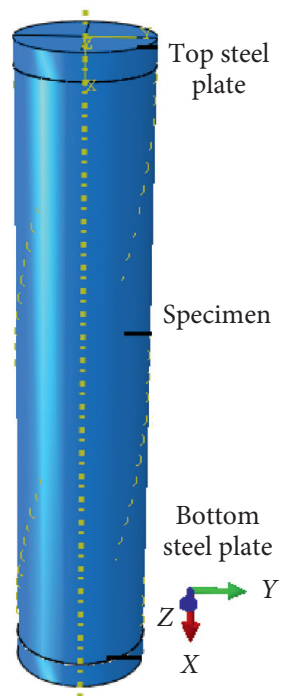

(a)

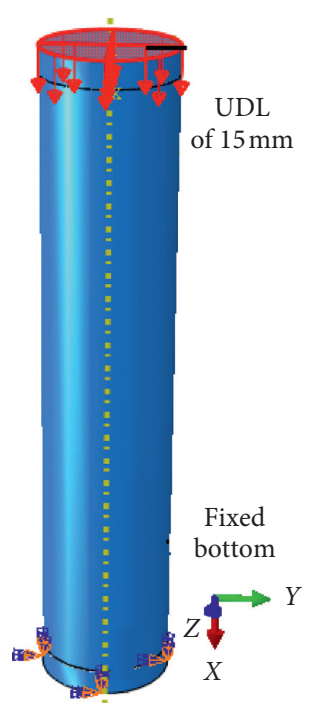

(b)

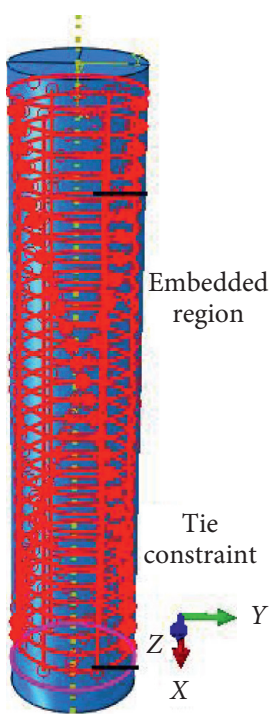

(c)

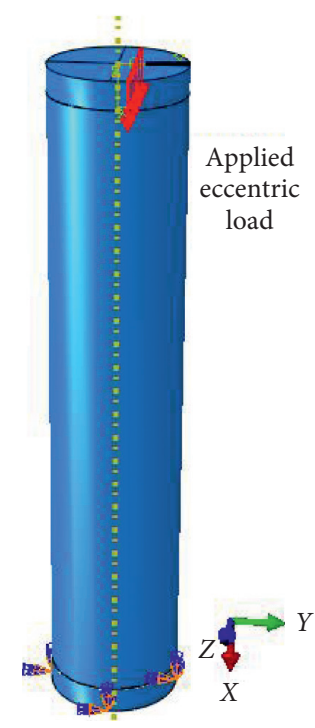

(d)

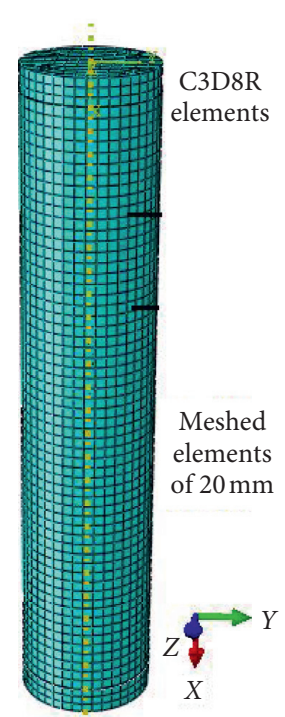

(e)

FIGURE 3: Simulated FEM: (a) geometry of HFRC column; (b) boundary conditions for concentric columns; (c) interaction between reinforcement and HFRC; (d) boundary conditions for an eccentric column; (e) constraints between load plates and column.

$k_{t} / k_{c} \geq 1$. Therefore, inequality $K_{c}^{\mathrm{hf}} \geq K_{c}$ will always clutch for the HFRC. Making the amendments for HFRC, the parameter $\sigma_{\mathrm{bo}}^{\mathrm{hf}} / \sigma_{\text {co }}^{\mathrm{hf}}$ can be theoretically measured by using equation (6) to be placed in the CDP model [48]:

$$
\frac{\sigma_{\mathrm{bo}}^{\mathrm{hf}}}{\sigma_{\mathrm{co}}^{\mathrm{hf}}}=\frac{k_{t}^{2}}{0.132 k_{c}}\left[\left(0.728-\frac{0.749}{k_{t}}\right)+\sqrt{\left(0.728-\frac{0.749}{k_{t}}\right)^{2}+\frac{0.03}{k_{t}^{2}}}\right] .
$$

The numerical value for the parameter $\sigma_{\mathrm{bo}}^{\mathrm{hf}} / \sigma_{\mathrm{co}}^{\mathrm{hf}}$ was obtained as 1.46 after placing the values of enhancing constants $\left(k_{c}\right.$ and $\left.k_{t}\right)$ in equation (6). When we use the values of enhancing constants as a unit representing the plain concrete, the value of 1.16 is secured for the parameter $\sigma_{\mathrm{bo}}^{\mathrm{hf}} / \sigma_{\mathrm{co}}^{\mathrm{hf}}$. The flow rule is measured by the parameter $\psi$ that is very useful for the accurate simulations of the concrete in ABAQUS. The value of $\psi$ will be less for HFRC as related to that of the plain concrete. The recommended value of $\psi$ locates between $31^{\circ}$ and $42^{\circ}$ for the plain concrete [50]. A theoretical model for the dilation angle of HFRC $\left(\psi^{\text {hf }}\right)$ can be reported in terms of $\lambda_{\text {pvaf }}$ and $\lambda_{\mathrm{pf}}$ [48]:

$$
\psi^{\mathrm{hf}}=\psi\left(1-0.861 \lambda_{\mathrm{pvaf}}-0.097 \lambda_{\mathrm{pf}}\right) .
$$

According to the elastic-plastic theory, the total strain $(\varepsilon)$ of concrete produced due to the application of load can be reported in two parts: one is the elastic strain $\left(\varepsilon^{\mathrm{el}}\right)$ and second is the plastic strain $\left(\varepsilon^{\mathrm{pl}}\right)$ of concrete:

$$
\varepsilon=\varepsilon^{\mathrm{el}}+\varepsilon^{\mathrm{pl}} .
$$

The nonlinearity of the concrete is associated with plastic, compression, and tensile damage behaviors of concrete. The strength and stiffness reduction of the concrete increase when the strain produced in the concrete increases because the damaging phenomenon is associated with the elastic and plastic parts of strain, i.e., $\varepsilon^{\mathrm{el}}$ and $\varepsilon^{\mathrm{pl}}$ [48]. The damage mechanism of HFRC can be fully defined in numerical simulations by two parameters: one is the compression damage parameter $\left(d_{c}\right)$ and the second is tension damage parameter $\left(d_{t}\right)$. These two parameters are used in the CDP model for the definition of damages produced by compression and tensile loads. Figure 4 reports the complete general stress-strain behavior of concrete subjected to compression loads. The compression stress of concrete $\left(\sigma_{c}\right)$ can be expressed by the following equation:

$$
\sigma_{c}=\left(1-d_{c}\right) E_{o}\left(\varepsilon_{c}-\varepsilon_{c}^{\mathrm{pl}}\right)
$$

In this model, $E_{o}$ indicates the modulus of elasticity of HFRC that can be measured using the equation provided by ACI 318-95 [46], $\varepsilon_{c}$ indicates the compression strain, and $\varepsilon_{c}^{\mathrm{pl}}$ is the plastic part of the compression strain of HFRC. The parameter $d_{c}$ was theoretically measured by using equation (10) as recommended by Wang and Chen [51]:

$$
d_{c}=\frac{1}{e^{-1 / m_{c}}-1}\left(e^{-\varepsilon_{c, \text { norm }}^{\text {in }} / m_{c}}-1\right) .
$$

In this model, the parameter $m_{c}$ is the controlling parameter for the speed of damaging evolution of concrete under compression having a value of 0.1 [52] and $\varepsilon_{\mathrm{c}, \text { norm }}^{\text {in }}$ is the standardized inelastic strain of concrete exposed to compression that can be denoted as $\varepsilon_{c}^{\text {in }} / \varepsilon_{\mathrm{cu}}^{\text {in }}$, where $\varepsilon_{\mathrm{cu}}^{\text {in }}$ is the strain equivalent to the standardized inelastic strain of concrete exposed to compression with a value of 0.033 [52]. Thus, the improved controlling parameter for HFRC under compression loads $\left(m_{c}^{\mathrm{hf}}\right)$ can be reported by the following equation [48]:

$$
m_{c}^{\mathrm{hf}}=m_{c}\left(1+a_{m 1} \lambda_{\mathrm{pvaf}}+b_{m 1} \lambda_{\mathrm{pf}}\right) \text {, }
$$

where $a_{m 1}$ and $b_{m 1}$ depict the constants that are associated with the characteristic parameter of different fibers with the 


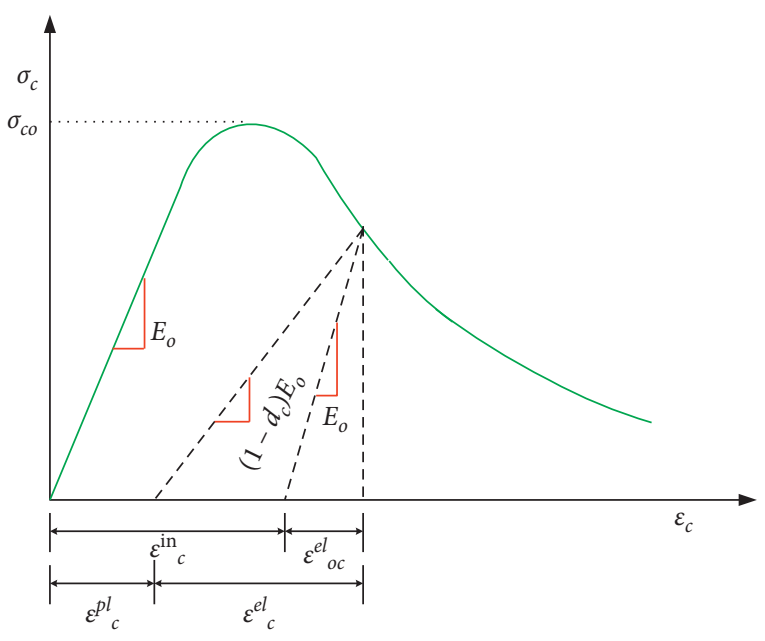

FIGURE 4: Stress-strain behavior of HFRC under compression.

values of 0.452 and 0.054 , respectively [48]. Therefore, the damage parameter under compression loads $d_{c}^{\text {hf }}$ and the compression stress $\left(\sigma_{c}^{\mathrm{hf}}\right)$ for the HFRC can be reported by the following equations, respectively:

$$
\begin{aligned}
& d_{c}^{\mathrm{hf}}=\frac{1}{e^{-1 / m_{c}^{\mathrm{hf}}}-1}\left(e^{-\varepsilon_{c, \text { norm }}^{\mathrm{in}} / m_{c}^{\mathrm{hf}}}-1\right), \\
& \sigma_{c}^{\mathrm{hf}}=\left(1-\frac{1}{e^{-1 / m_{c}^{\mathrm{hf}}}-1}\left(e^{-\varepsilon_{c, \text { norm }}^{\mathrm{in}} / m_{c}^{\mathrm{hf}}}-1\right)\right) E_{o}\left(\varepsilon_{c}-\varepsilon_{c}^{\mathrm{pl}}\right) .
\end{aligned}
$$

For determining the maximum compression stress $\left(\sigma_{\mathrm{co}}^{\mathrm{hf}}\right)$ and the corresponding compression strain $\left(\varepsilon_{\mathrm{co}}^{\mathrm{hf}}\right)$ of the HFRC, the following models were employed in the present work [48]:

$$
\begin{gathered}
\sigma_{\mathrm{co}}^{\mathrm{hf}}=\sigma_{\mathrm{co}}\left(1+0.206 \lambda_{\mathrm{pvaf}}+0.388 \lambda_{\mathrm{pf}}\right), \\
\varepsilon_{\mathrm{co}}^{\mathrm{hf}}=\varepsilon_{\mathrm{co}}\left(1+0.705 \lambda_{\text {pvaf }}+0.364 \lambda_{\mathrm{pf}}\right) .
\end{gathered}
$$

The postcracking and propagation of cracks are reduced, and the ductility of concrete is improved by the addition of fibers. The postcracking performance of HFRC can be welldefined by the strain-hardening and a strain-softening portion of the stress-strain curve. The behavior of concrete before achieving the peak load can be well-defined by the strain-hardening, and the strain-softening defines the postcollapse behavior [53]. Figure 5 reports the complete stress-strain performance of HFRC under tensile loading from which the models for the compression stress of HFRC can be presented in the following form:

$$
\sigma_{t}=\left(1-d_{t}\right) E_{o}\left(\varepsilon_{t}-\varepsilon_{t}^{\mathrm{pl}}\right),
$$

where $\varepsilon_{t}$ depicts the tensile strain of HFRC and $\varepsilon_{t}^{\mathrm{pl}}$ is the plastic parts of the tensile strain of HFRC. The constant $d_{t}$ was well-defined by using equation (17) as recommended by Wang and Chen [51]:

$$
d_{t}=\frac{1}{e^{-1 / m_{t}}-1}\left(e^{-\varepsilon_{t, \mathrm{corm}}^{\mathrm{ck}} / m_{t}}-1\right) .
$$

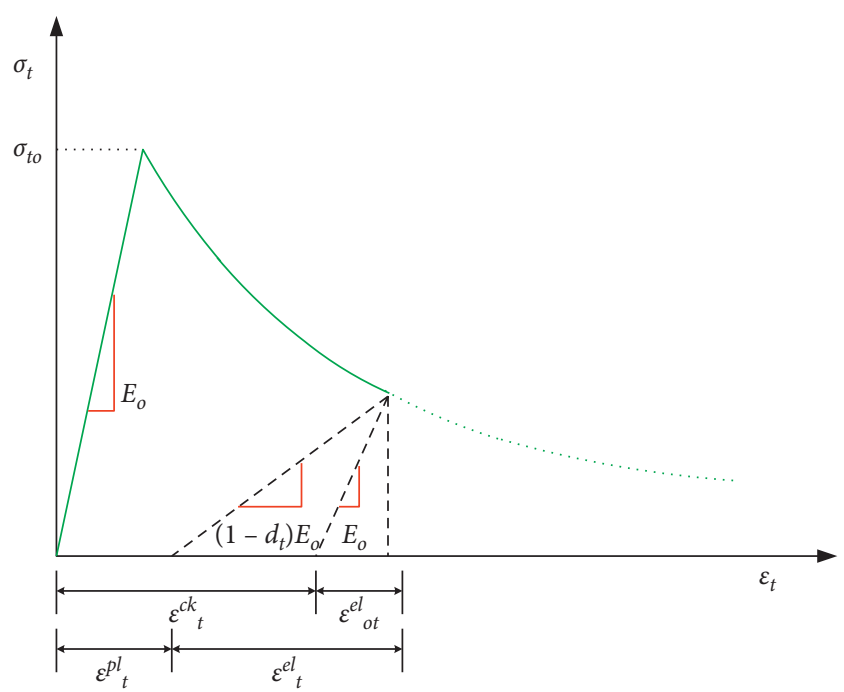

FIgURE 5: Stress-strain behavior of HFRC under tension.

In this model, the parameter $m_{t}$ is the controlling parameter for the speed of damaging evolution of concrete under tension having a value of 0.05 [52] and $\varepsilon_{t, \text { norm }}^{\mathrm{ck}}$ is the standardized inelastic strain of HFRC exposed to tension that can be reported as $\varepsilon_{t}^{\mathrm{ck}} / \varepsilon_{\mathrm{tu}}^{\mathrm{ck}}$, where, $\varepsilon_{\mathrm{tu}}^{\mathrm{ck}}$ is the strain corresponding to the standardized inelastic strain of HFRC exposed to tension with a value of 0.0033 [52]. The improved controlling constant for HFRC in tension $\left(m_{t}^{\mathrm{hf}}\right)$ can be reported by the following equation [48]:

$$
m_{t}^{\mathrm{hf}}=m_{t}\left(1+a_{m 2} \lambda_{\text {pvaf }}+b_{m 2} \lambda_{\mathrm{pf}}\right),
$$

where $a_{m 2}$ and $b_{m 2}$ depict the constants that are linked to the characteristic parameter of PVA and PF with the values of 0.628 and 0.156 , respectively [48]. Therefore, the damage parameter in tension $d_{t}^{\mathrm{hf}}$ and tensile stress $\left(\sigma_{t}^{\mathrm{hf}}\right)$ for the HFRC can be reported by the following equations, respectively:

$$
\begin{aligned}
& d_{t}^{\mathrm{hf}}=\frac{1}{e^{-1 / m_{t}^{\mathrm{hf}}}-1}\left(e^{-\varepsilon_{t, \mathrm{norm}}^{\mathrm{ck}} / m_{t}^{\mathrm{hf}}}-1\right), \\
& \sigma_{t}^{\mathrm{hf}}=\left(1-\frac{1}{e^{-1 / m_{t}^{\mathrm{hf}}}-1}\left(e^{-\varepsilon_{t, \mathrm{porm}}^{\mathrm{ck}} / m_{t}^{\mathrm{hf}}}-1\right)\right) E_{o}\left(\varepsilon_{t}-\varepsilon_{t}^{\mathrm{pl}}\right) .
\end{aligned}
$$

The maximum tensile stress $\left(\sigma_{\mathrm{to}}^{\mathrm{hf}}\right)$ and the corresponding tensile strain $\left(\varepsilon_{\mathrm{to}}^{\mathrm{hf}}\right)$ of the HFRC can be theoretically measured using the following models [48]:

$$
\begin{gathered}
\sigma_{\text {to }}^{\text {hf }}=\sigma_{\text {to }}\left(1+0.379 \lambda_{\text {pvaf }}+0.020 \lambda_{\text {pf }}\right), \\
\varepsilon_{\text {to }}^{\text {hf }}=\varepsilon_{\text {to }}\left(1+0.498 \lambda_{\text {pvaf }}+0.697 \lambda_{\text {pf }}\right) .
\end{gathered}
$$

3.3. Simulation of GFRP Bars. The modeling of HFRC was performed in ABAQUS by considering them 3-D stress elements. The modeling of GFRP bars and spirals was performed by considering them as 3-D wire elements. The 
perfect bond between the HFRC and GFRP bars was defined using the 'embedded region' constraint present in ABAQUS. Different properties of the reinforcement were taken according to Table 2. Poisson's ratio of GFRP material was considered as 0.25 [28], and a linear elastic model up to failure for employed for the definition of GFRP bars as recommended by the literature $[2,25,28]$. The linear elastic behavior of GFRP bars is reported in Figure 6. The GFRP bars were considered having their compressive strength as half of the tensile strength [54].

3.4. Calibration of the Finite Element Model. For the finite element simulations, it is essential to validate the predictions using experimental results. In the present study, a control model (AA38-0ECC) was selected whose load-defection performance was employed for the calibration and validation purpose of the control FEM. The calibration process of the control FEM was performed for various geometrical and material parameters of GFHF columns. Different boundary conditions were also employed to select the most suitable constraints for the accurate predictions. The calibration for the plastic behavior of HFRC included the viscosity parameter $(\mu)$ only. All the other parameters of HFRC were theoretically measured using the modified equations provided in the previous section of this study. Various mesh sizes and the different types of elements were also assessed to secure the most accurate predictions compared with the testing measurements. When the control FEM was calibrated for different boundary conditions, the most accurate predictions were obtained for fixing all the degrees of freedom at the bottom and the top end was kept free for all the translational and rotational degrees of freedom. The different values used to examine the influence of $\mu$ on the load-deflection performance of control specimen (AA380ECC) were $0.0096,0.0080,0.0064,0.0048,0.0032$, and 0.0016 . For securing the close agreement with the testing results, the value of this parameter should be small [55]. The influence of $\mu$ on the load-deflection performance of the control specimen was reported in Figure 7(a). The value of 0.0032 for $\mu$ portrayed a close correlation with the testing results.

For avoiding the discontinuity of strain and stress spreading and to obtain accurate numerical results, the sensitivity analysis of the load-deflection performance of the control specimen due to the mesh size was carried out. The size of the elements should be kept small enough to give accuracy and large enough to avoid the numerical convergence issues. Figure 7(b) reports the sensitivity analysis of load-deflection performance due to an investigation of mesh sizes of $70 \mathrm{~mm}, 60 \mathrm{~mm}, 50 \mathrm{~mm}$, $40 \mathrm{~mm}, 30 \mathrm{~mm}, 20 \mathrm{~mm}$, and $10 \mathrm{~mm}$. The close agreement was found using a $20 \mathrm{~mm}$ size of elements. The studied elements of the HFRC were triangular, hexahedral elements, and tetrahedral elements available in ABAQUS. The best performance of the control model was obtained when the C3D8R elements for HFRC and T3D2R elements for the GFRP bars and spirals were employed as evidenced from the literature $[2,24,48]$.

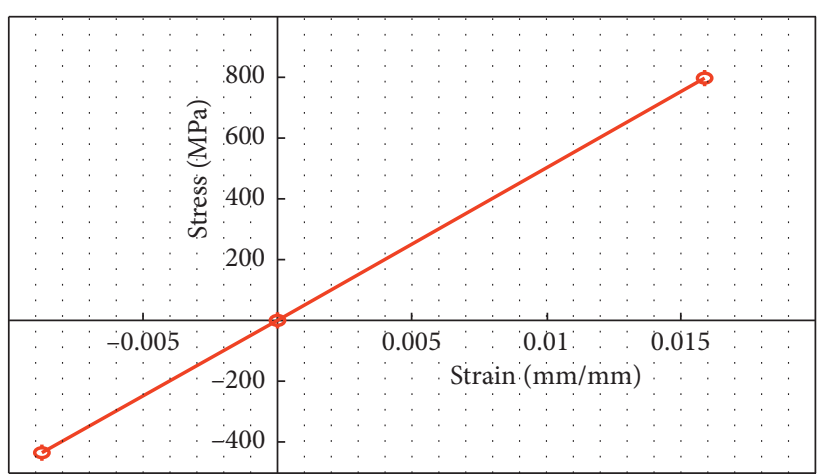

Figure 6: Linear elastic behavior of the GFRP material.

\section{Experimental Results}

4.1. Column Strength of Specimens. The column AA380ECC portrayed the ultimate axial compression strength with a value of $2678 \mathrm{kN}$. The axial compression strength portrayed by the column with a double spacing of spirals (AA75-0ECC) was $2403 \mathrm{kN}$. This value was $10.2 \%$ lower than the axial compression strength of the specimen with a half spacing of the spirals. It depicts that the decrease in the axial compression strength is larger for the GFHF columns with the enhancement in the spacing of GFRP spirals. Consequently, the GFHF columns with a lesser pitch of GFRP spirals or with larger transverse confinement are more effective in terms of axial compression strength. The axial compression strength is meaningfully exaggerated by the application of testing eccentricity. The average percent reduction in the axial compression strength was $24.8 \%$ and $58.2 \%$ for the GFHF columns with the testing eccentricity of $30 \mathrm{~mm}$ and $60 \mathrm{~mm}$, respectively. The axial compression strength of column AA38-30ECC was 2.7\% larger than AA75-30ECC, but the column with $60 \mathrm{~mm}$ eccentricity portrayed a conflicting behavior. The axial compression strength was larger for the column with a higher spacing of GFRP spirals, i.e., the axial compression strength of AA75-60ECC was $10 \%$ larger than the axial compression strength of AA3860ECC. This depicts that the GFHF specimens under comparatively higher testing eccentricities are more effective in terms of axial compression strength when the spacing of GFRP spirals is higher.

4.2. Failure Modes. When the axial compression load was applied on the top surface of the columns, their behavior was linear elastic up to $90 \%$ of the peak load. At this stage, there were no cracks developed on the surface of the HFRC, and the lateral confinement mechanism of GFRP spirals was not activated. When the load was increased form the peak load, the cracking of the HFRC cover was initiated by sparking the small vertical hairline cracks on the compression portion of the specimens producing a small sound. The vertical hairline cracks spread vertically, and their width improved with the application of a more enhanced load. After securing the maximum axial 


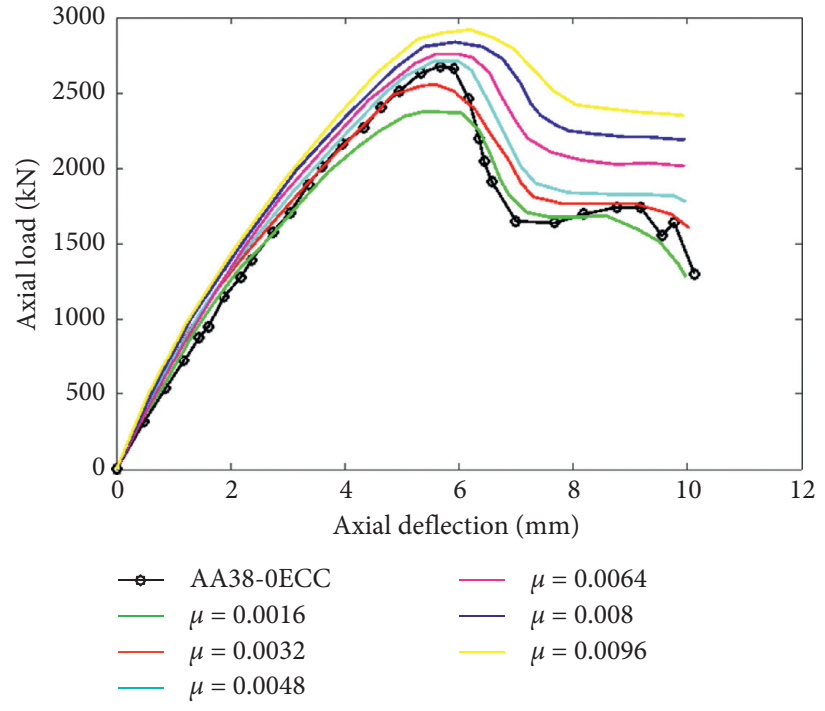

(a)

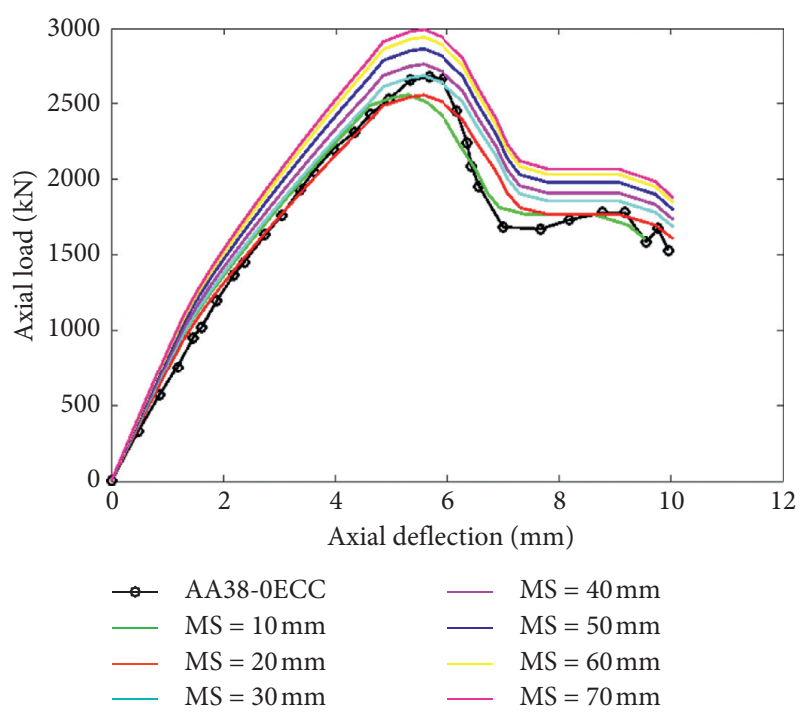

(b)

FIGURE 7: Effect of (a) viscosity parameter $(\mu)$ and (b) mesh size (MS) on the load-deflection performance of the control specimen.

compression strength of the specimens, the rate of improvement in the axial strain was lifted by forming the long vertical cracks along with the height of the specimens. At this stage, the development in the HFRC cover happened, and the restriction influence provided by the lateral GFRP spirals was initiated. After getting to about $70 \%$ of the ultimate axial compression load in the postpeak failure stage, the transverse GFRP spirals achieved their maximum axial compression strength producing a sound of rupture. Most of the specimens failed in the upper or lower half regions. During the damaging phenomenon, GFRP bars were fractured in GFHF specimens. For the columns with a lesser spacing of spirals (AA38-0ECC, AA38-60ECC, and AA3830ECC), the failure happened due to the rupturing of GFRP spirals and the crushing of HFRC core.

The performance of eccentric columns was similar. The axial compression strength of the columns improved constantly until the transmission of hairline vertical cracks on the compressive portion of the columns happened. Mainly, the failure of eccentric specimens occurred due to the crushing of HFRC on the compression portion of the columns. The tension side of these columns depicted the flexural-tension failure mechanism that also caused the decrease of the axial compression strength of specimens. No serious spalling of the HFRC cover was observed after the failure of columns because of the bridging influence due to the incorporation of PVA and PF fibers in the concrete which avoid the cracking and decrease the crack spreading.

4.3. Effect of Pitch of Spirals. As shown in earlier works, the AS of the columns was enhanced with the reduction in the pitch of lateral confinement $[44,56]$. The same pattern of AS reduction was found for concentric and eccentric specimens. As the pitch of the spirals decreased from $75 \mathrm{~mm}$ (a volumetric ratio of 1.46 percent) to $38 \mathrm{~mm}$ (a volumetric ratio of 2.88 percent), the increase was 4.52 percent in AS of the concentric column. This improvement in the axial compression strength is due to the good confinement and restrained GFRP bars and effective lateral detention of the HFRC material by the tightly spaced spirals to take in more energy [56]. As the pitch of the spirals increased, the axial deflection contributing to the ultimate AS enhanced. When the spiral pitch was raised from $38 \mathrm{~mm}$ to $75 \mathrm{~mm}$, the axial deflection enhancement equivalent to the ultimate AS was $0.58 \%$. Figure 8 shows the pitch effect of spirals.

The loading eccentricity of the GFHF specimen of $30 \mathrm{~mm}$ showed no substantial difference in the load-deflection response and an increase in the spiral pitch from $38 \mathrm{~mm}$ to $75 \mathrm{~mm}$, whereas the GFHF specimen exposed eccentricity of $60 \mathrm{~mm}$ showed higher AS and high associated deflection at the larger pitch of spirals demonstrating that the GFHF columns are more effective under loading eccentricity with a greater pitch of GFRP spirals.

4.4. Effect of Loading Eccentricity. Due to the application of loading eccentricity, a substantial reduction in the AS of all columns occurred. Figure 9 demonstrates the influence of loading eccentricity on the AS of the specimens tested. The AS of the GFHF columns with a spiral pitch of $38 \mathrm{~mm}$ was decreased from $2678 \mathrm{kN}$ to $1933 \mathrm{kN}$ and $1005 \mathrm{kN}$ indicating a decrease of 27.82 percent and 62.46 percent in the AS when the eccentricity was increased from $0 \mathrm{~mm}$ to $30 \mathrm{~mm}$ and $0 \mathrm{~mm}$ to $60 \mathrm{~mm}$. Furthermore, the AS of the GFHF columns with a spiral pitch of $75 \mathrm{~mm}$ decreased from $2403 \mathrm{kN}$ to $1879 \mathrm{kN}$ and $1106 \mathrm{kN}$ showing a decrease of 21.80 percent and 53.97 percent in AS while the eccentricity increased from $0 \mathrm{~mm}$ to $30 \mathrm{~mm}$ and $0 \mathrm{~mm}$ to $60 \mathrm{~mm}$, respectively. Therefore, due to geometric imperfections and design defects, the minor eccentricities produced should be minimized because they cause a 


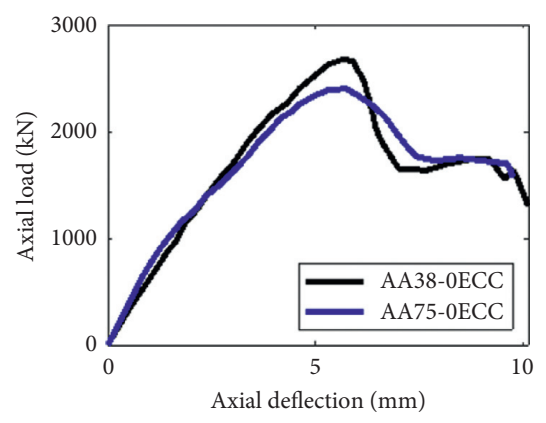

(a)

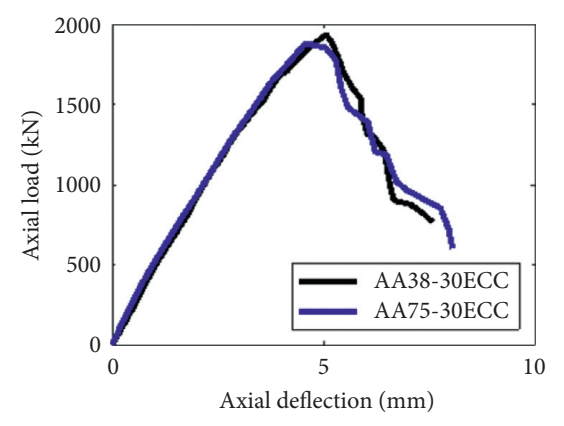

(b)

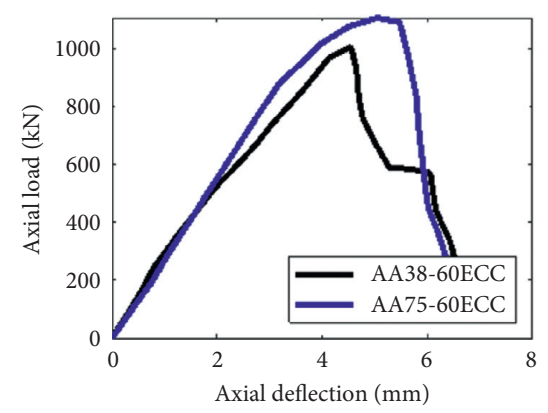

(c)

FIGURE 8: Effect of the pitch of spirals on the load-deflection response of GFHF columns.

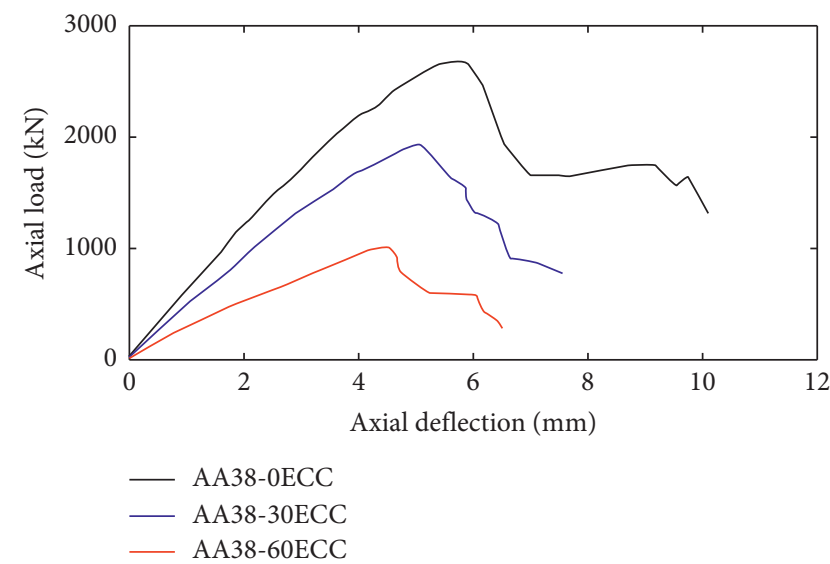

(a)

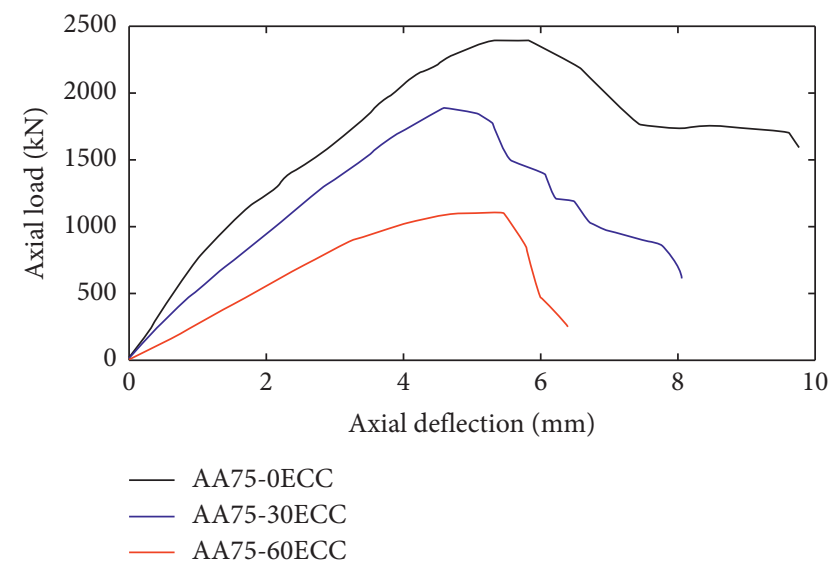

(b)

FIGURE 9: Influence of eccentricity on the AS of the GFHF columns.

considerable reduction in the strengths of concrete elements.

\section{Results and Discussions}

5.1. Peak Strength and Corresponding Deflection. Table 4 presents the observed data and the FEM estimates for the ultimate AS and subsequent deflection of all the GFHF specimens tested. The FEM of the $30 \mathrm{~mm}$ eccentric GFHF column (AA38-30ECC) showed a minimum difference of 1.22 percent concerning the AS. For the specimens AA75-30ECC and AA38-60ECC, respectively, the maximum and minimum disparities for axial deflection compared concerning the ultimate axial force were noticed. Such high percentages of errors may be due to the initial geometric inconsistency of the specimens during the manufacturing process which was not measured in the current study. The average error for the GFHF test specimen was 2.44 percent and 3.71 percent, respectively, for the axial force and associated axial deflection. The presented FEM mostly misjudged the ultimate AS for columns of the GFHF. Figure 10 illustrates a comparative study of the experimental and FEA analyses for the ultimate AS.
As for the eccentrically loaded columns, the proposed FEM correctly described the sensitivity of load-deflection. The average difference between the results obtained and the FEM responses for the ultimate strength and related deflection of the eccentric columns was $2.18 \%$ and $4.56 \%$. These minor differences represent that the modeling of HFRC's tensile behavior was done exactly in the current study, and the currently proposed FEM is sufficiently accurate to simulate GFHF column behavior.

5.2. Complete Load-Deflection Curves. The maximum loaddeflection curves of the GFHF columns estimated from experiments and simulated from FEM are shown in Figure 11. These curves demonstrate that the proposed FEM estimated accurately the behavior of GFHF column load-deflection in the elastic range with some variance in the postpeak collapse point. The FEM of the AA75-30ECC and AA75-60ECC specimens reported stiffer responses in the elastic limit, whereas the FEM of all the specimens exceeded the postpeak performance. The variations in the postpeak collapse stage shown by the FEM results can be due to the concept of HFRC degradation and damaging modes and the constraints supposed between the reinforcing bars and HFRC. Through working on certain 
TABle 4: Experimental and FEA results of axial peak load $\left(P_{\mathrm{u}}\right)$ and axial deflection at $P_{\mathrm{u}}$.

\begin{tabular}{|c|c|c|c|c|c|c|}
\hline \multirow[b]{2}{*}{ Sample label } & \multicolumn{2}{|c|}{ Experimental results } & \multicolumn{2}{|r|}{ FEM results } & \multirow[b]{2}{*}{$\begin{array}{l}\% \text { age difference in } \\
P_{\mathrm{u}}\end{array}$} & \multirow[b]{2}{*}{$\begin{array}{c}\% \text { age difference in deflection } \\
\text { at } P_{\mathrm{u}}\end{array}$} \\
\hline & $\underset{(\mathrm{KN})}{P_{\mathrm{u}}}$ & $\begin{array}{l}\text { Axial deflection at } P_{\mathrm{u}} \\
(\mathrm{mm})\end{array}$ & $\begin{array}{c}P_{\mathrm{u}} \\
(\mathrm{KN})\end{array}$ & $\begin{array}{l}\text { Axial deflection at } P_{\mathrm{u}} \\
(\mathrm{mm})\end{array}$ & & \\
\hline $\begin{array}{l}\text { AA38- } \\
\text { 0ECC }\end{array}$ & 2678 & 5.66 & 2557 & 5.56 & 4.49 & 1.77 \\
\hline $\begin{array}{l}\text { AA38- } \\
30 \text { ECC }\end{array}$ & 1933 & 5.05 & 1909 & 5.34 & 1.22 & 5.74 \\
\hline $\begin{array}{l}\text { AA38- } \\
60 \mathrm{ECC}\end{array}$ & 1005 & 4.54 & 1019 & 4.60 & 1.40 & 1.32 \\
\hline $\begin{array}{l}\text { AA75- } \\
\text { 0ECC }\end{array}$ & 2403 & 5.73 & 2369 & 5.86 & 1.41 & 2.27 \\
\hline $\begin{array}{l}\text { AA75- } \\
30 \text { ECC }\end{array}$ & 1879 & 4.56 & 1812 & 4.97 & 3.56 & 8.99 \\
\hline $\begin{array}{l}\text { AA75- } \\
60 \text { ECC }\end{array}$ & 1106 & 5.05 & 1134 & 5.16 & 2.54 & 2.18 \\
\hline
\end{tabular}

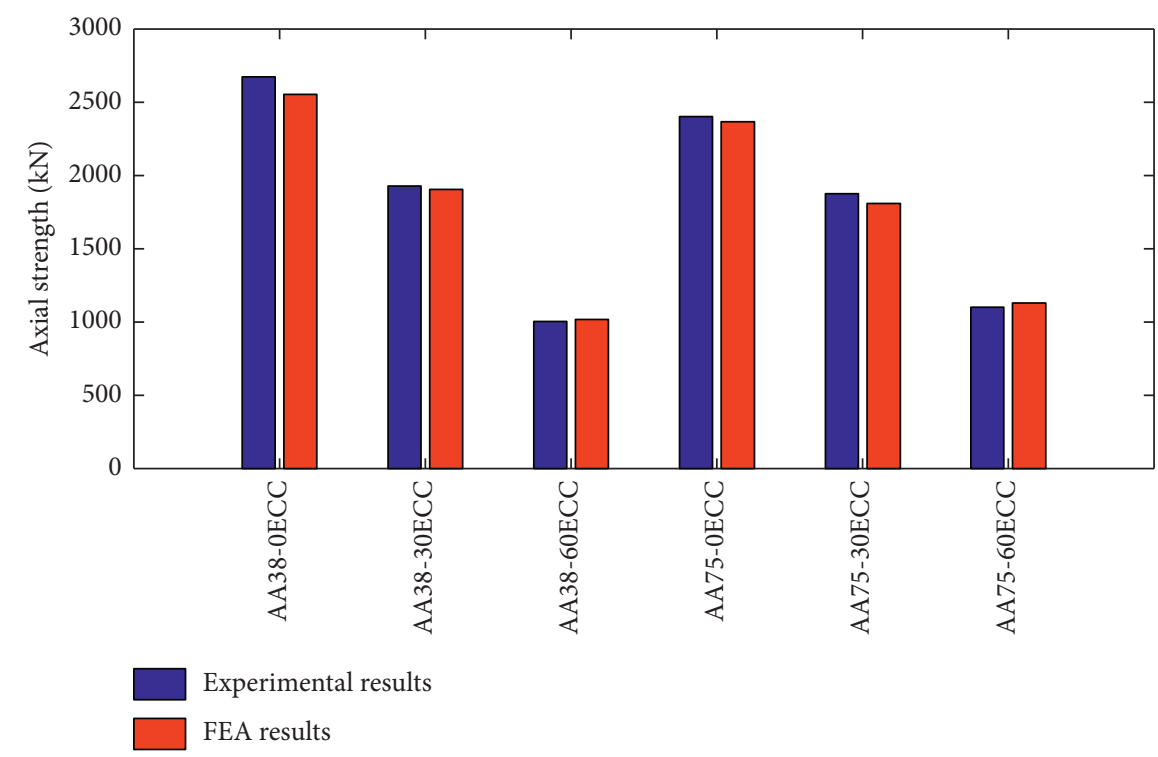

Figure 10: Comparison of experimental and FEA results for the peak AS of specimens.

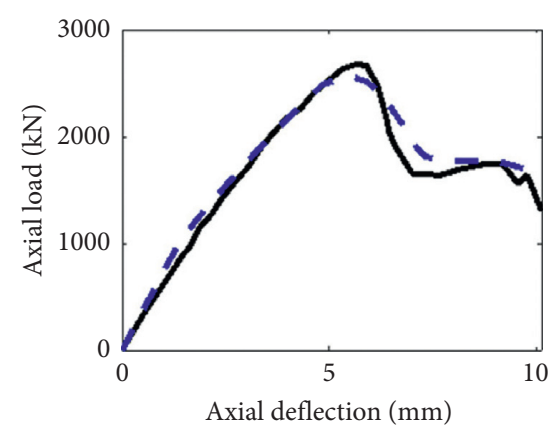

AA38-0ECC (Exp)

- - AA38-0ECC (FEA)

(a)

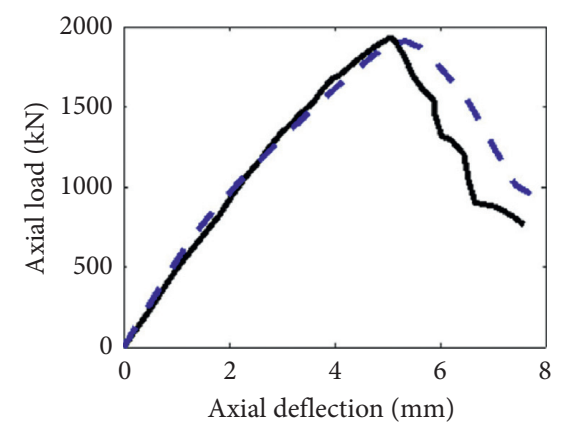

- AA38-30ECC (Exp)

- - AA38-30ECC (FEA)

(b)

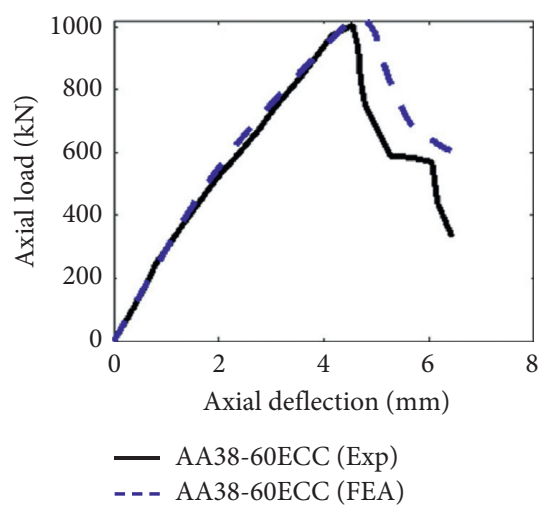

(c)

Figure 11: Continued. 


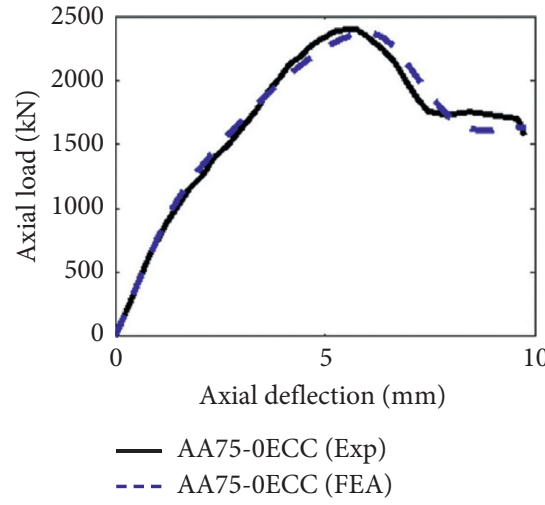

(d)

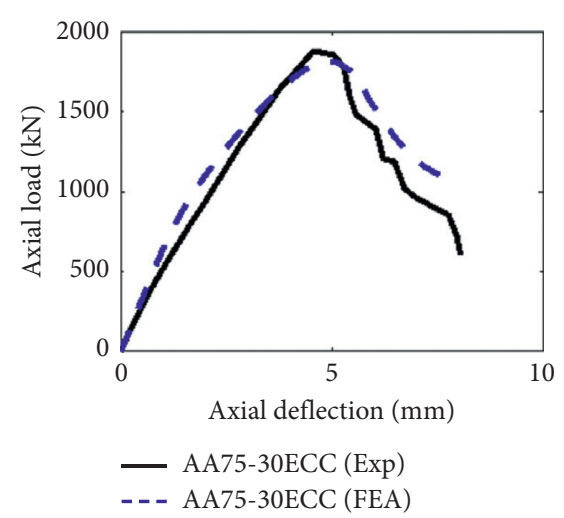

(e)

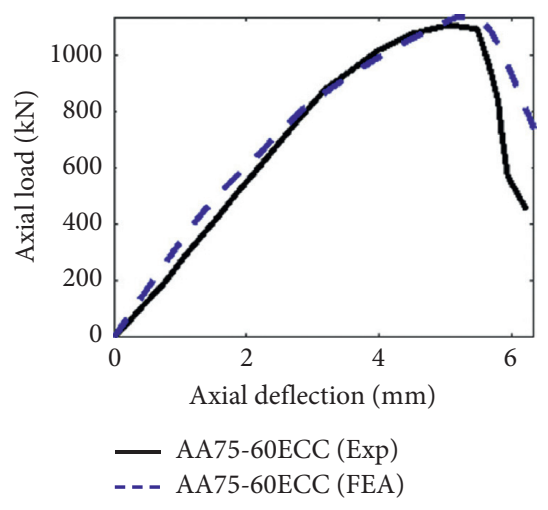

(f)

FIGURE 11: Comparison of load-deflection curves of GFHF columns obtained from FEM and experiments.

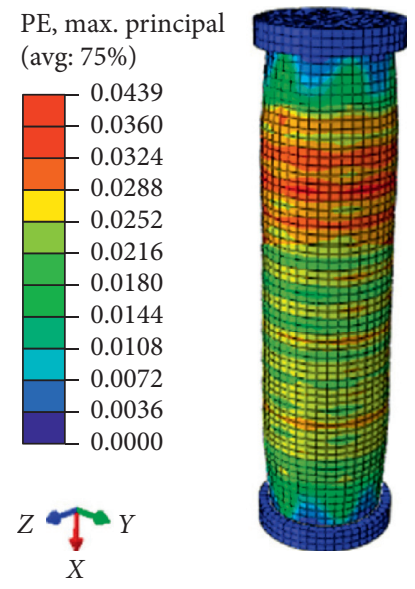

(a)

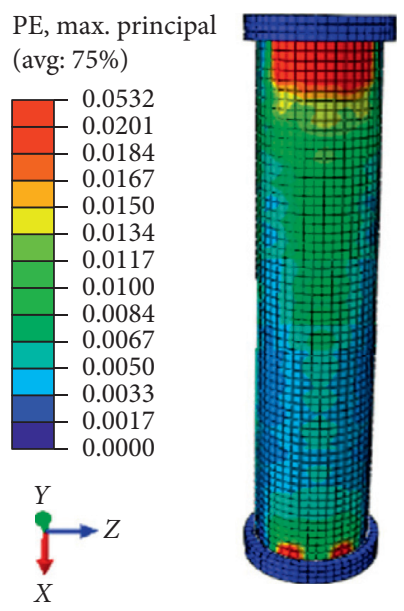

(e)
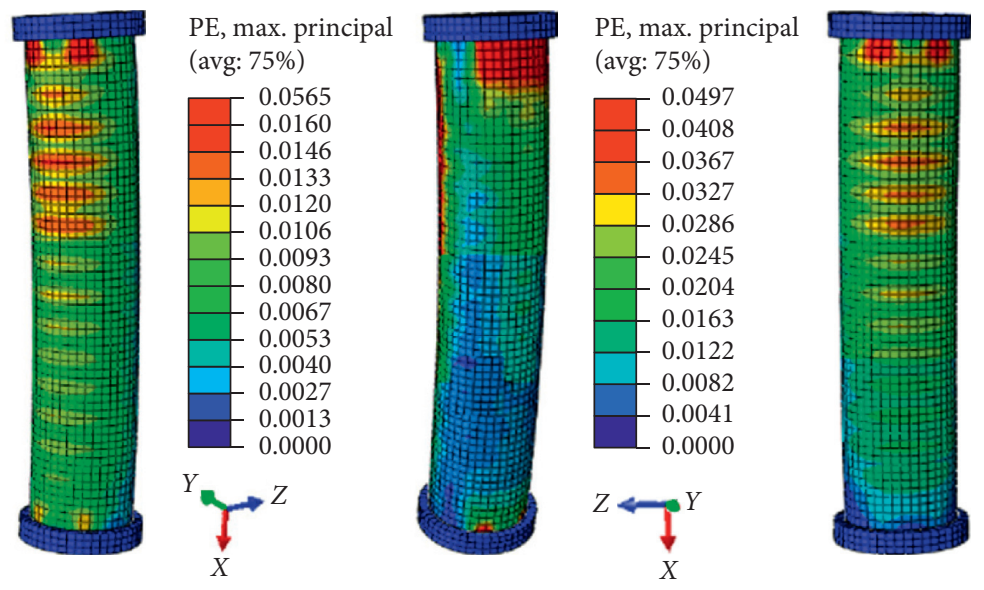

(c)

(d)

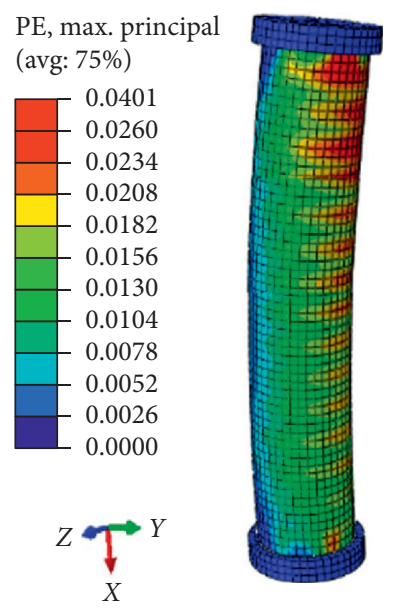

(f)

Figure 12: Overview of GFHF specimens obtained from FEM testing. (a) AA38-0ECC; (b) AA38-30ECC; (c) AA38-60ECC; (d) AA750ECC; (e) AA75-30ECC; (f) AA75-60ECC.

parameters in detail, the findings can be further improved. However, the proposed FEM successfully estimated the overall response of the load-deflection curve of GFHF columns.
5.3. Failure Modes and Crack Patterns. Figure 12 presents the damage quantification of cracks based on experimental study and FEM simulations. The crack trends in finite element models can be illustrated precisely by the 
positive principal plastic strain since the path of the cracks in concrete is perpendicular to this sort of strain $[2,30,57,58]$. Thus, in the present study, the simulation of GFHF column failure modes and cracking behaviors was done using such strains. It was concluded that the proposed FEM modeled all the specimens' failure modes and cracking trends in a well-conforming way with the experimental work. After obtaining the ultimate AS, concrete cover spalling was undertaken together with reinforcement yielding. The failure mainly occurred in the upper portion of the specimens which was correctly predicted by the FEM. In close correlation with the test results, the proposed FEM also forecast the failure mechanisms and cracking behavior of the eccentrically loaded columns. The presumption of a good bond between HFRC and GFRP is strong compared with that of HFRC steel reinforcement. GFRP bars have lower elasticity modules like that of HFRC than steel bars. Therefore, strong alignment between the GFRP reinforcing bars and HFRC can be established.

\section{Conclusions}

The present research was carried out to investigate the structural performance of GFHF columns by conducting tests and numerical simulations. The numerical simulations were conducted using a modified damaged plastic model to predict the complex damaging behavior of HFRC. From this work, the following key points could be drawn:

(1) The experimental tests and numerical simulations based on the complex equations depicted that the identical modes of failure for all the GFHF columns were observed. The failure mechanism either in the upper half section or in the lower half section with a ruptured sound of longitudinal GFRP bars and spirals of GFRP after reaching their ultimate strength.

(2) The loading eccentricity induced the AS of GFHF columns to decrease significantly. Owing to loading eccentricities of $30 \mathrm{~mm}$ and $60 \mathrm{~mm}$, the average reduction in the AS of GFHF columns was 25 percent and 58 percent, respectively.

(3) The reduction in the pitch of spirals led to an increase in the AS of GFHF column. As the pitch of the GFRP spiral dropped from $75 \mathrm{~mm}$ to $38 \mathrm{~mm}$, the AS of concentrically loaded GFHF columns increased by 10 percent.

(4) The finite element model had been proposed using a modified CDP model for the concrete having hybrid fibers. The relative difference between the FEM estimates and the experimental results of GFHF column was 2.4 percent for AS and 3.7 percent for the deflections at ultimate AS. The proposed FEM solidly exhibited its applicability to effectively describe the full load-deflection curves and the failure modes of specimens. Thus, the comparative studies firmly confirm the effectiveness of the proposed numerical models for forecasting the performance of GFHF columns using the suggested complex system of equations.

\section{Data Availability}

The data used to support the findings of this study are available from the corresponding author upon request.

\section{Conflicts of Interest}

The authors have no conflicts of interest.

\section{Acknowledgments}

This research project was funded by the Zhejiang University of China.

\section{References}

[1] H. J. Zadeh and A. Nanni, "Design of RC columns using glass FRP reinforcement," Journal of Composites for Construction, vol. 17, no. 3, pp. 294-304, 2012.

[2] A. Raza, Q. U. Z. Khan, and A. Ahmad, "Numerical investigation of load-carrying capacity of GFRP-reinforced rectangular concrete members using CDP model in ABAQUS," Advances in Civil Engineering, vol. 2019, Article ID 1745341, 2019.

[3] M. Elchalakani, M. Dong, A. Karrech, A. Mohamed, S. Mohamed, and J. S. Huo, "Circular concrete columns and beams reinforced with GFRP bars and spirals under axial, eccentric, and flexural loading," Journal of Composites for Construction, vol. 24, no. 3, Article ID 04020008, 2020.

[4] A. Raza, S. A. Raheel Shah, M. M. Khan et al., "Axial loadcarrying capacity of steel tubed concrete short columns confined with advanced FRP composites," Periodica Polytechnica Civil Engineering, vol. 64, no. 3, 2020.

[5] B. Benmokrane, E. El-Salakawy, A. El-Ragaby, and T. Lackey, "Designing and testing of concrete bridge decks reinforced with glass FRP bars," Journal of Bridge Engineering, vol. 11, no. 2, pp. 217-229, 2006.

[6] A. Raza and Q. U. Z. Khan, "Experimental and numerical behavior of hybrid fiber reinforced concrete compression members under concentric loading," SN Applied Sciences, vol. 2, no. 4, 2020.

[7] P. Paultre, R. Eid, Y. Langlois, and Y. Lévesque, "Behavior of steel fiber-reinforced high-strength concrete columns under uniaxial compression," Journal of Structural Engineering, vol. 136, no. 10, pp. 1225-1235, 2010.

[8] T. A. Hales, C. P. Pantelides, and L. D. Reaveley, "Analytical buckling model for slender FRP-reinforced concrete columns," Composite Structures, vol. 176, pp. 33-42, 2017.

[9] H.-L. Dong, Z. Wang, and Y. Sun, "Axial compressive behavior of square concrete columns reinforced with innovative closed-type winding GFRP stirrups," Composite Structures, vol. 192, pp. 115-125, 2018.

[10] C. C. Wang, I. E. Harik, and H. Gesund, "Strength of rectangular concrete columns reinforced with fiber-reinforced polymer bars," ACI Structural Journal, vol. 103, no. 3, p. 452, 2006. 
[11] M. Z. Afifi, H. M. Mohamed, and B. Benmokrane, "Axial capacity of circular concrete columns reinforced with GFRP bars and spirals," Journal of Composites for Construction, vol. 18, no. 1, Article ID 04013017, 2013.

[12] C. P. Pantelides, M. E. Gibbons, and L. D. Reaveley, "Axial load behavior of concrete columns confined with GFRP spirals," Journal of Composites for Construction, vol. 17, no. 3, pp. 305-313, 2013.

[13] L. Sun, M. Wei, and N. Zhang, "Experimental study on the behavior of GFRP reinforced concrete columns under eccentric axial load," Construction and Building Materials, vol. 152, pp. 214-225, 2017.

[14] M. Hadi, H. Karim, and M. N. Sheikh, "Experimental investigations on circular concrete columns reinforced with GFRP bars and helices under different loading conditions," Journal of Composites for Construction, vol. 20, no. 4, Article ID 04016009, 2016.

[15] M. Elchalakani, G. Ma, F. Aslani, and W. Duan, "Design of GFRP-reinforced rectangular concrete columns under eccentric axial loading," Magazine of Concrete Research, vol. 69, no. 17 , pp. $865-877,2017$.

[16] H. Karim, M. N. Sheikh, and M. N. S. Hadi, "Axial load-axial deformation behaviour of circular concrete columns reinforced with GFRP bars and helices," Construction and Building Materials, vol. 112, pp. 1147-1157, 2016.

[17] H. J. Mohammed and M. F. M. Zain, "Simulation assessment and theoretical verification of a new design for portable concrete barriers," KSCE Journal of Civil Engineering, vol. 21, no. 3, pp. 851-862, 2017.

[18] C. Park, M. M. A. Khater, A.-H. Abdel-Aty et al., "Dynamical analysis of the nonlinear complex fractional emerging telecommunication model with higher-order dispersive cubic-quintic," Alexandria Engineering Journal, vol. 59, no. 3 , pp. 1425-1433, 2020.

[19] M. M. Khater and D. Baleanu, "On abundant new solutions of two fractional complex models," Advances in Difference Equations, vol. 2020, no. 1, pp. 1-14, 2020.

[20] A.-H. Abdel-Aty, M. M. A. Khater, R. A. M. Attia, M. AbdelAty, and H. Eleuch, "On the new explicit solutions of the fractional nonlinear space-time nuclear model," Fractals, vol. 28, no. 8, Article ID 2040035, 2020.

[21] M. M. A. Khater, R. A. M. Attia, C. Park, and D. Lu, "On the numerical investigation of the interaction in plasma between (high \& low) frequency of (Langmuir \& ion-acoustic) waves," Results in Physics, vol. 18, p. 103317, 2020.

[22] X. Attia, X.-J. He, and Y.-C. Yang, "Numerical simulation of GFRP reinforced concrete beams," Advances in Materials Science and Engineering, vol. 2017, Article ID 5386498, 10 pages, 2017.

[23] V.-T. Pham, S. Vaidyanathan, and T. Kapitaniak, "Complexity, dynamics, control, and applications of nonlinear systems with multistability," Complexity, vol. 2020, Article ID 8510930, 7 pages, 2020.

[24] N. F. Hany, E. G. Hantouche, and M. H. Harajli, "Finite element modeling of FRP-confined concrete using modified concrete damaged plasticity," Engineering Structures, vol. 125, pp. 1-14, 2016.

[25] A. M. A. Ibrahim, M. F. M. Fahmy, and Z. Wu, "3D finite element modeling of bond-controlled behavior of steel and basalt FRP-reinforced concrete square bridge columns under lateral loading," Composite Structures, vol. 143, pp. 33-52, 2016.

[26] B. Alfarah, F. López-Almansa, and S. Oller, "New methodology for calculating damage variables evolution in Plastic
Damage Model for RC structures," Engineering Structures, vol. 132, pp. 70-86, 2017.

[27] X. Zhang and Z. Deng, "Experimental study and theoretical analysis on axial compressive behavior of concrete columns reinforced with GFRP bars and PVA fibers," Construction and Building Materials, vol. 172, pp. 519-532, 2018.

[28] M. Elchalakani, A. Karrech, M. Dong, M. S. Mohamed Ali, and B. Yang, "Experiments and finite element analysis of GFRP reinforced geopolymer concrete rectangular columns subjected to concentric and eccentric axial loading," Structures, vol. 14, pp. 273-289, 2018.

[29] A. Raza, B. Ali, M. A. Nawaz, and I. Ahmed, "Structural performance of FRP-RC compression members wrapped with FRP composites," Structures, vol. 27, pp. 1693-1709, 2020.

[30] A. Ahmad, Q. UZ. Khan, and A. Raza, "Reliability analysis of strength models for CFRP-confined concrete cylinders," Composite Structures, vol. 244, Article ID 112312, 2020.

[31] G. Boscato and S. Ientile, "Experimental and numerical investigation on dynamic properties of thin-walled GFRP buckled columns," Composite Structures, vol. 189, pp. 273285, 2018.

[32] M. M. A. Khater, R. A. M. Attia, A.-H. Abdel-Aty, W. Alharbi, and D. Lu, "Abundant analytical and numerical solutions of the fractional microbiological densities model in bacteria cell as a result of diffusion mechanisms," Chaos, Solitons \& Fractals, vol. 136, Article ID 109824, 2020.

[33] A.-H. Attia, M. M. A. Khater, H. Dutta, J. Bouslimi, and M. Omri, "Computational solutions of the HIV-1 infection of CD4+ T-cells fractional mathematical model that causes acquired immunodeficiency syndrome (AIDS) with the effect of antiviral drug therapy," Chaos, Solitons \& Fractals, vol. 139, Article ID 110092, 2020.

[34] H. Khater, M. Khater, and R. A. Attia, "Inelastic interaction and blowup new solutions of nonlinear and dispersive long gravity waves," Journal of Function Spaces, vol. 2020, Article ID 5362989, 10 pages, 2020.

[35] C. Yue, M. M. A. Khater, R. A. M. Attia, and D. Lu, “The plethora of explicit solutions of the fractional KS equation through liquid-gas bubbles mix under the thermodynamic conditions via Atangana-Baleanu derivative operator," Advances in Difference Equations, vol. 2020, no. 1, pp. 1-12, 2020.

[36] G. Turvey and Y. Zhang, "A computational and experimental analysis of the buckling, postbuckling and initial failure of pultruded GRP columns," Computers \& Structures, vol. 84, no. 22-23, pp. 1527-1537, 2006.

[37] A. Raza and Q. U. Z. Khan, "Structural behavior of GFRPreinforced circular HFRC columns under concentric and eccentric loading," Arabian Journal for Science and Engineering, pp. 1-14, 2020.

[38] A. Raza, Q. U. Z. Khan, and A. Ahmad, "Prediction of axial compressive strength for FRP-confined concrete compression members," KSCE Journal of Civil Engineerig, vol. 24, pp. 2099-2109, 2020.

[39] M. Elchalakani, A. Karrech, M. Dong, M. S. Mohamed Ali, G. Li, and B. Yang, "Testing and modelling of geopolymer concrete members with fibreglass reinforcement," Proceedings of the Institution of Civil Engineers-Structures and Buildings, pp. 1-16, 2019.

[40] ASTM-C150/C150M-18, Standard Specification for Portland Cement, ASTM International, West Conshohocken, PA, USA, 2018.

[41] D. U. A. Galagedera and P. Silvapulle, "Experimental evidence on robustness of data envelopment analysis," Journal of the Operational Research Society, vol. 54, no. 6, pp. 654-660, 2003. 
[42] R. L. Raab and R. W. Lichty, "Identifying subareas that comprise a greater metropolitan area: the criterion of county relative efficiency," Journal of Regional Science, vol. 42, no. 3, pp. 579-594, 2002.

[43] G. B. Maranan, A. C. Manalo, B. Benmokrane, W. Karunasena, and P. Mendis, "Behavior of concentrically loaded geopolymer-concrete circular columns reinforced longitudinally and transversely with GFRP bars," Engineering Structures, vol. 117, pp. 422-436, 2016.

[44] M. Elchalakani and G. Ma, "Tests of glass fibre reinforced polymer rectangular concrete columns subjected to concentric and eccentric axial loading," Engineering Structures, vol. 151, pp. 93-104, 2017.

[45] Y. Chi, L. Xu, and H.-S. Yu, "Plasticity model for hybrid fiberreinforced concrete under true triaxial compression," Journal of Engineering Mechanics, vol. 140, no. 2, pp. 393-405, 2014.

[46] D. J. Hand, H. Mannila, and P. Smyth, Principles of Data Mining (Adaptive Computation and Machine Learning), MIT Press, Cambridge, MA, USA, 2001.

[47] G. G. Triantafyllou, T. C. Rousakis, and A. I. Karabinis, "Corroded RC beams patch repaired and strengthened in flexure with fiber-reinforced polymer laminates," Composites Part B: Engineering, vol. 112, pp. 125-136, 2017.

[48] Y. Chi, M. Yu, L. Huang, and L. Xu, "Finite element modeling of steel-polypropylene hybrid fiber reinforced concrete using modified concrete damaged plasticity," Engineering Structures, vol. 148, pp. 23-35, 2017.

[49] J. Lubliner, J. Oliver, S. Oller, and E. Oñate, "A plastic-damage model for concrete," International Journal of Solids and Structures, vol. 25, no. 3, pp. 299-326, 1989.

[50] J. Wu, J. Li, and R. Faria, "An energy release rate-based plasticdamage model for concrete," International Journal of Solids Structures, vol. 43, no. 3-4, pp. 583-612, 2006.

[51] J. Wang and Y. Chen, ABAQUS Application in Civil Engineering, Zhejiang University Press, Zhejiang, China, 2006.

[52] Z. Huang and J. Y. R. Liew, "Nonlinear finite element modelling and parametric study of curved steel-concrete-steel double skin composite panels infilled with ultra-lightweight cement composite," Construction and Building Materials, vol. 95, pp. 922-938, 2015.

[53] Y. Chi and L. Xu, "Constitutive modeling of steel-polypropylene hybrid fiber reinforced concrete using a non-associated plasticity and its numerical implementation," Composite Structures, vol. 111, pp. 497-509, 2014.

[54] M. Yu, M. Dong, A. Karrech et al., "Behaviour and design of air-cured GFRP-reinforced geopolymer concrete square columns," Magazine of Concrete Research, vol. 71, no. 19, pp. 1006-1024, 2018.

[55] K. Barth and $\mathrm{H}$. Wu, "Efficient nonlinear finite element modeling of slab on steel stringer bridges," Finite Elements in Analysis and Design, vol. 42, no. 14-15, pp. 1304-1313, 2006.

[56] M. Elchalakani, M. Dong, A. Karrech, G. Li, M. S. Mohamed, and B. Yang, "Experimental investigation of rectangular aircured geopolymer concrete columns reinforced with GFRP bars and stirrups," Journal of Composites for Construction, vol. 23, no. 3, Article ID 04019011, 2019.

[57] A. S. Genikomsou and M. A. Polak, "Finite element analysis of punching shear of concrete slabs using damaged plasticity model in ABAQUS," Engineering Structures, vol. 98, pp. 3848, 2015.

[58] A. Raza, S. A. R. Shah, A. R. Khan et al., "Sustainable FRPconfined symmetric concrete structures: an application experimental and numerical validation process for reference data," Applied Sciences, vol. 10, no. 1, p. 333, 2020. 